\title{
Sexual behavior in men during COVID-19
}

\author{
Dernando Nestor Facio Junior ${ }^{1}$ \\ (D) Maria Fernanda Warick Facio ${ }^{2}$ \\ (iD) Ana Clara Nagle Spessoto ${ }^{3}$ \\ (iD) Luis Cesar Fava Spessoto ${ }^{1}$
}

1. Professor de Urologia, Departamento de Urologia. Faculdade de Medicina de São José do Rio Preto (FAMERP/FUNFARME), São José do Rio Preto, SP, Brasil. 2. Médica, Faculdade de Medicina (FACERES), São losé do Rio Preto, SP, Brasil. 3. Graduanda, Faculdade de Medicina de Catanduva (UNIFIPA), Catanduva, SP, Brasil.

KEYWORDS: Coronavirus; pornography; testosterone.

The rapid changes that have occurred during this pandemic have influenced people in various ways, affecting stress levels, finances, and health. As the world faces this situation, it is adjusting to a new reality involving the need for social distancing and a change in habits'. We do not know what the lasting effects of the COVID-19 pandemic will be on patterns of sexual behavior. Social distancing affects all aspects of daily life and it is not clear whether it affects the sexual habits of married partners.

As the period of quarantine is prolonged, understanding changes in sexual behavior may provide information regarding potentially unhealthy sexual attitudes. This crisis is contributing to the experimentation of addictive sexual behaviors, such as those practiced via the internet ${ }^{2}$. A pornography sharing website observed an increase in the use of free pornography during the quarantine, especially in Spain (61\%) and Italy (57\%). Similar patterns have been observed in the United States and regions of Asia, especially with regard to morning viewing ${ }^{3}$. Besides the consumption of this content by the adult population, the pandemic is exerting a negative impact on the physical, intellectual, emotional, and sexual activities of adolescents. When emotions are high and adolescents are more socially isolated, there can be an increase in the use of online pornography, the effects of which have implications in terms of emotional and relational problems in this generation ${ }^{4}$. Online content is active and portable, enabling fast and easy access through a variety of electronic devices, in which it is difficult for parents to monitor online media ${ }^{5}$.

Although the majority of adolescents in the cognitive and volitional age may not experience consequences, some cases could generate a reduction in desire, an increase in masturbatory practices, and a reduced interest in real sex due to the gap between what is possible and what is being fantasized, which could lead to potential health problems in terms of dependence, paraphilias, and sexual disorders ${ }^{5,6}$.

Another vulnerable population in this pandemic is composed of men older than 60 years of age, $66.2 \%$ of whom could develop more severe forms of the disease $^{7,8}$. Androgen deficiency in this age group can exert a negative impact on multiple organs and quality of life ${ }^{9}$. Therefore, the maintenance of testosterone

DATE OF SUBMISSION: 12-Jul-2020

DATE OF ACCEPTANCE: 08-Aug-2020

CORRESPONDING AUTHOR: Fernando Nestor Facio Junior

Av. Fernando Correa Pires, 3600, Departamento de Urologia, Faculdade de Medicina (FAMERP/FUNFARME), S. José do Rio Preto, SP, Brasil

Tel: +55 17 98164-5376 / Fax: +55 17 3232-0199

E-mail:fnfacio@yahoo.com.br 
therapy is necessary. Low levels of this hormone may play a physiopathological role associated with SARS$\mathrm{CoV}-2$, as the worsening of hypogonadism with androgen depletion can contribute to the severe course of the disease and even death ${ }^{10}$.

Besides these complications amidst the pandemic, low levels of testosterone in men older than 60 years of age can further aggravate the lack of libido and low energy, generating profound suffering due to the negative impact on sexual behavior. Thus, specialized, multidisciplinary care is needed, with online medical appointments aimed at the continuation of hormone replacement therapy. Considering the relationship between mental and sexual health, these patients need close follow-up, as they may be at greater risk of manifesting preexisting sexual dsyfunctions ${ }^{11}$.

\section{Conflicts of interest}

The authors have nothing to disclose

\section{Funding}

None.

\section{Author's Contribution}

All authors have contributed equally to the work.

\section{REFERENCES}

1. World Health Organization. Defining sexual health. Geneva: World Health Organization; 2020. [cited 2020 May 17]. Available from: https://www.who.

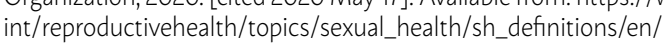

2. Bonenberger $A$. Falling through the cracks in quarantine [cited 2020 Mar 23]. Available from: https://medicine.yale.edu/news/yale-medicine-magazine/ falling-through-the-cracks-in-quarantine/

3. Pornhub. Coronavirus insights. [cited 2020 Mar 23]. Available from: https:// www.pornhub.com/insights/corona-virus

4. Landripet I, Štulhofer A. Is pornography use associated with sexual difficulties and dysfunctions among younger heterosexual men? J Sex Med. 2015;12(5):1136-9.

5. Collins RL, Strasburger VC, Brown JD, Donnerstein E, Lenhart A, L Ward LM, et al. Sexual media and childhood well-being and health. Pediatrics. 2017;140(Suppl. 2):S162-6.

6. Pizzol D, Bertoldo A, Foresta C. Adolescents and web porn: a new era of sexuality. Int J Adolesc Med Health. 2016;28(2):169-73.

7. Zhou F, Yu T, Du R, Fan G, Liu Y, Liu Z, et al. Clinical course and risk factors for mortality of adult in patients with COVID-19 in Wuhan, China: a retrospective cohort study. Lancet. 2020;395(10229):1054-62.

8. Guan WJ, Liang WH, Zhao Y, Liang HR, Chen ZS, Li YM, et al; China Medical Treatment Expert Group for COVID-19. Comorbidity and its impact on 1590 patients with COVID-19 in China: a nationwide analysis. Eur Respir 1. 2020;55(5):2000547.

9. Bhasin S, Brito |P, Cunningham GR, Hayes F|, Hodis HN, Matsumoto AM, et al. Testosterone therapy in men with hypogonadism: an endocrine society clinical practice guideline. J Clin Endocrinol Metab. 2018;103(5):1715-44.

10. Salonia A, Corona G, Giwercman A, Maggi M, Minhas S, Nappi RE, et al. SARS-CoV-2, testosterone and frailty in males (PROTEGGIMI): a multidimensional research project. Andrology. 2020. doi:10.1111/andr.12811.

11. Miranda EP, Nascimento B, Torres LO, Glina S. Challenges in the practice of sexual medicine in the time of COVID-19 in Brasil. J Sex Med. 2020;17(7):1222-4. 